Recent Advances in Communication, Electronics \& Electrical Engineering

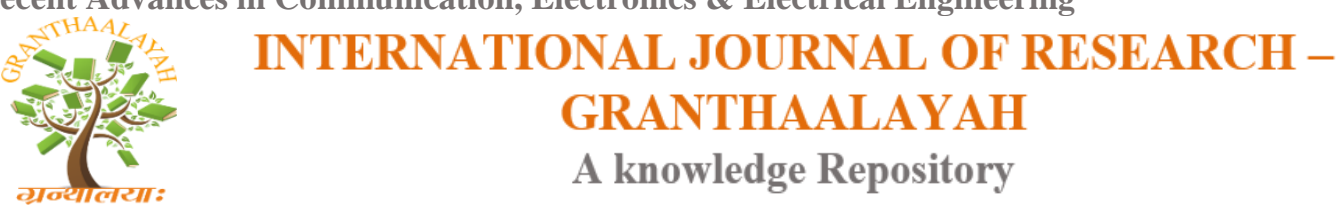

RACEEE - 17

\title{
WIRELESS POWER THEFT MONITORING SYSTEM
}

\author{
Sai Supriya G K ${ }^{1}$, Priyamvadaa $\mathbf{R}^{2}$, Savita Sangappa Mulimani ${ }^{3}$ \\ 1, 2, 3 Department of E\&C(DEC), Dayananda Sagar College for PG-Studies, Bengaluru, India
}

DOI: https://doi.org/10.29121/granthaalayah.v5.i4RACEEE.2017.3333

\begin{abstract}
Now-a-days in Public Service Sectors, their Automation is the updated trend, which transforms the manpower dependent services to semi-automatic or full-automatic Sectors. Since, because the country is enlightened to globalization, income of people is rising. This "Busy" word has now become vital part of everybody's life. So, governments prefer not only to give quality service but also the corrupt \& error free services to its citizens. So as an upshot, the project proposed which is an advanced system, helps Electricity-Corporations or Electricity-Boards to switch to advancement towards "anti-Power theft" smoothly. This project helps inorder to give quality service to its customer without any kind of problems, along with an aim of reducing recurring theft of energy to a considerable extent.
\end{abstract}

Keywords: RF Receiver and Transmitter; Buffer; Driver; Relay; GSM; Microcontroller.

Cite This Article: Sai Supriya G K, Priyamvadaa R, and Savita Sangappa Mulimani. (2017). "WIRELESS POWER THEFT MONITORING SYSTEM." International Journal of Research Granthaalayah, 5(4) RACEEE, 118-123. 10.29121/granthaalayah.v5.i4RACEEE.2017.3333.

\section{Introduction}

Pilferage of electricity is a criminal practice by stealing electric power. It is considered as a crime and liable for punishment by heavy fines and, in some cases, -jail. Mainly, the basic method of stealing electricity is: a 'direct wire-connection' to the main power supply-route which would be passing by a house or shops so that, electricity can flow to consumer without crossing the electric-meter installed by a government-agency which provides electrical-services to customers. Other methods would include: opening the meter itself, without damaging its seal and reversing the dials, which might be complicated and requires expert skill ${ }^{[4][6]}$. It's been an "invisible" crime often. Like: illegitimately hooks into a power supply or hooks-up-a-line that disconnected, or May tampers a meter inorder to affect the correct recording of electricity usage. Law abiding electricity consumers don't do these activities, hence the big impact of electricitytheft emphasising the danger, is usually unrecognized. Power theft carries fatal risks. Many thieves pay their-lives while stealing power. Electricity-theft is not just dangerous for the people who steal, even If you are on the same line, and then you might pay the cost for their attempt of 
Recent Advances in Communication, Electronics \& Electrical Engineering

stealing too. The power-line might be over-loaded with electric energy, which might harm electronic-gadgets and appliances at domestic level that are designed to receive a particular, steady-amount of electricity. Electric-power-pilferage makes power-service less-reliable and diminished-quality for paying-customers. Electricity thieves may be even un-knowingly feed energy back into the line of power, which usually has dangerous effects for line-man who usually assume that the power-line they are going to work on is de-energized.

So, the foremost motivation of this project is the current in-efficient distribution-system of the Electricity-Boards all over the world. Also, the present inability of the concerned-authorities in applying the existing laws in a strict form has encouraged more and more people to lead towards such illegitimate activities. In case, we develop an effective and efficient system to remotely monitor the usage of power and are able to detect power-pilferage at the exact location in an accurate and cost effective way, such massive-losses can be prevented. This kind of money could be definitely used for the development of the quality services of electricity board.

Safe Electricity tells that, everyone can help each-other in-order to prevent miss-use and reduce power pilferage through following the measures as mentioned below:

- Intimate the respective electricity department immediately if, experienced any illegitimately connected-customer.

- Don't cut-off or tamper seal on the provide meter-base in any situation or reason.

- If you don't have a legitimate connection of power line apply for concerned electricity board for one power line.

- Intimate the concerned departments if any illegitimate usage persists in your surrounding and be awake.

\section{Materials and Methods}

\section{Methodology}

Here electricity board will transmit the energy via RF-Transmitter. At the user end, the RFReceiver receives the transmitted power from the Electricity Board and then provides an acknowledgement about the reception of power, by activating a Micro Switch. The acknowledgement information will be transmitted to the head office via RF-Transmitter. This is the basic way of operation employed in the proposed methodology.

While coming to the part of Theft-identification, there are 2 stages of Detection:

- Alarm beep, with message alert

- Fine levied, with message intimation

Stage-1: The electricity board will transmit energy via RF-Transmitter which has to be received by RF-Receiver at user-end. If there is any malicious actions implied onto the receiver, the acknowledgement of reception will not be reverted back to RF-Transmitter. If this violation situation happens for the $1^{\text {st }}$ time, a beep-alarm of theft is made with an alerting message sent to the destination (for example: to a pre-decided mobile, of electricity-board) through the 
Recent Advances in Communication, Electronics \& Electrical Engineering employment of GSM, intimating about theft with a specified message "ELECTRICITY THEFT".

Stage-2: If the lapse of acknowledgement again persists from being reverted back to the RFTransmitter by surpassing the permissible $1^{\text {st }}$ alert, then a fine of pre-fixed amount (assume Rs.100) is levied on the user and the supply line to the user is also disconnected automatically (load cut-off) with a specified message sent via GSM as: "ELECTRICITY THEFT" and "FINE: $100 "$ ".

\section{Block diagram}

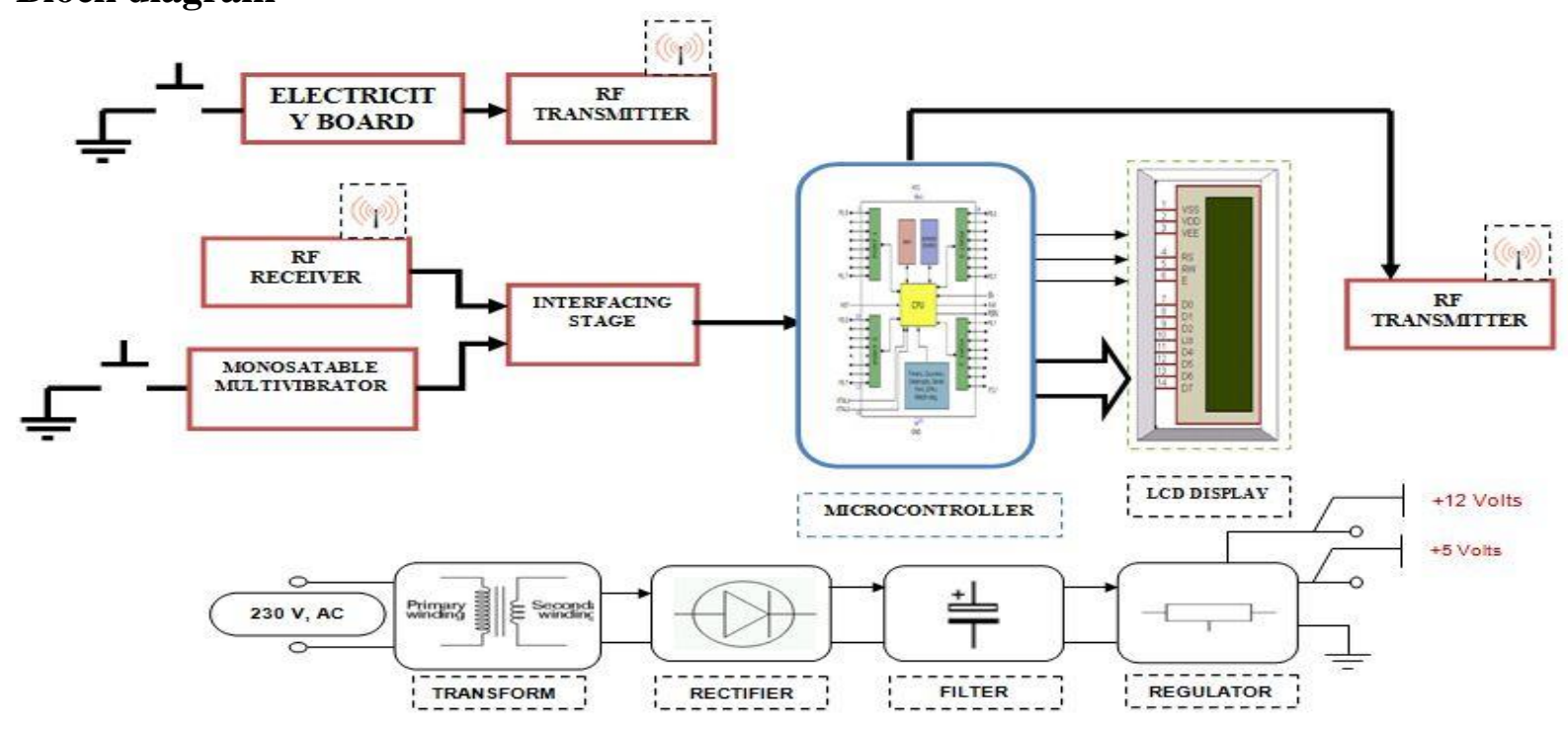

HARDWARE REOUIREMENTS: MICROCONTROLIER (89C51), LCD, Relay Driver, Relays, Resistors, Capacitors, LeDs, Crystal, Diodes, Transformer, Voltage Regulator, Push Button SOFTWARE REOUIREMENTS:

MICROCONTROLIER (89C51), LCD, Relay Driver, Relays, Res istors. Capacitors, LED
Keil compiler uVision 3, Language: Embedded C or Assembly, wLPRO Programmer

Figure 1: Block Schematic of composite Transmitter Block

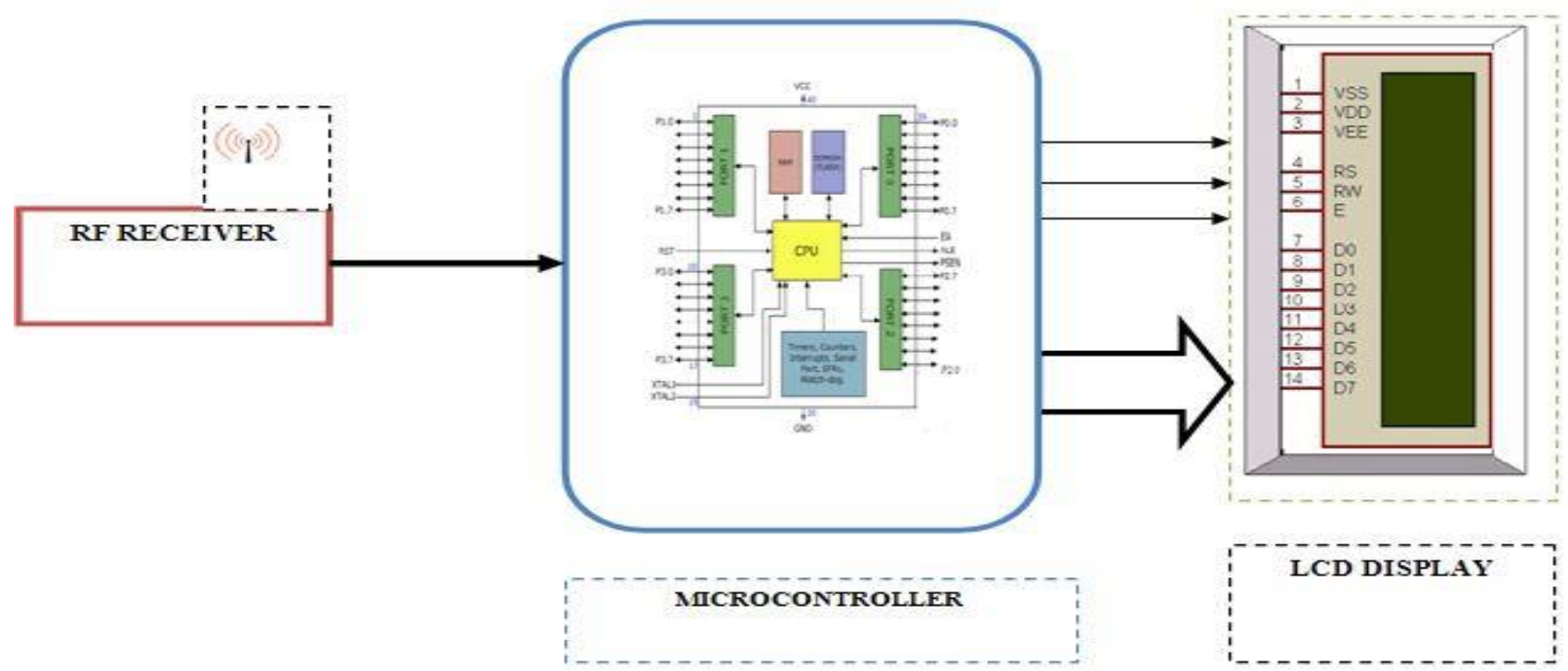

Figure 2: Block Schematic of composite Receiver Block 
Recent Advances in Communication, Electronics \& Electrical Engineering

\section{Block Schematic Description:}

- The system consists of Power-supply unit, RF-transmitter, RF-receiver, Buffers, Drivers, Relays, Indicator

- For proposed system we use intentionally designed two power-supply voltages of $+5 \mathrm{~V}$ and $+12 \mathrm{~V}$ inorder to obtain regulated supply of power.

- RF-transmitters inorder to transmit the radio signals to a pre-determined destination placed at a certain distance from transmitter block.

- RF-receiver inorder to receive the transmitted radio signals from a distant receiver.

- Buffers employed inorder to provide the extra current drive at the output part of the receiver.

- Driver is used inorder to drive the relays employed in the transmitter part.

- Relay is used inorder to drive the load connected across the block of user.

- Indicator: two types of indicators are used for the system. They are buzzer and the LED. Buzzer for an alarm effect in case of theft persistence and LED in case of active load condition indication.

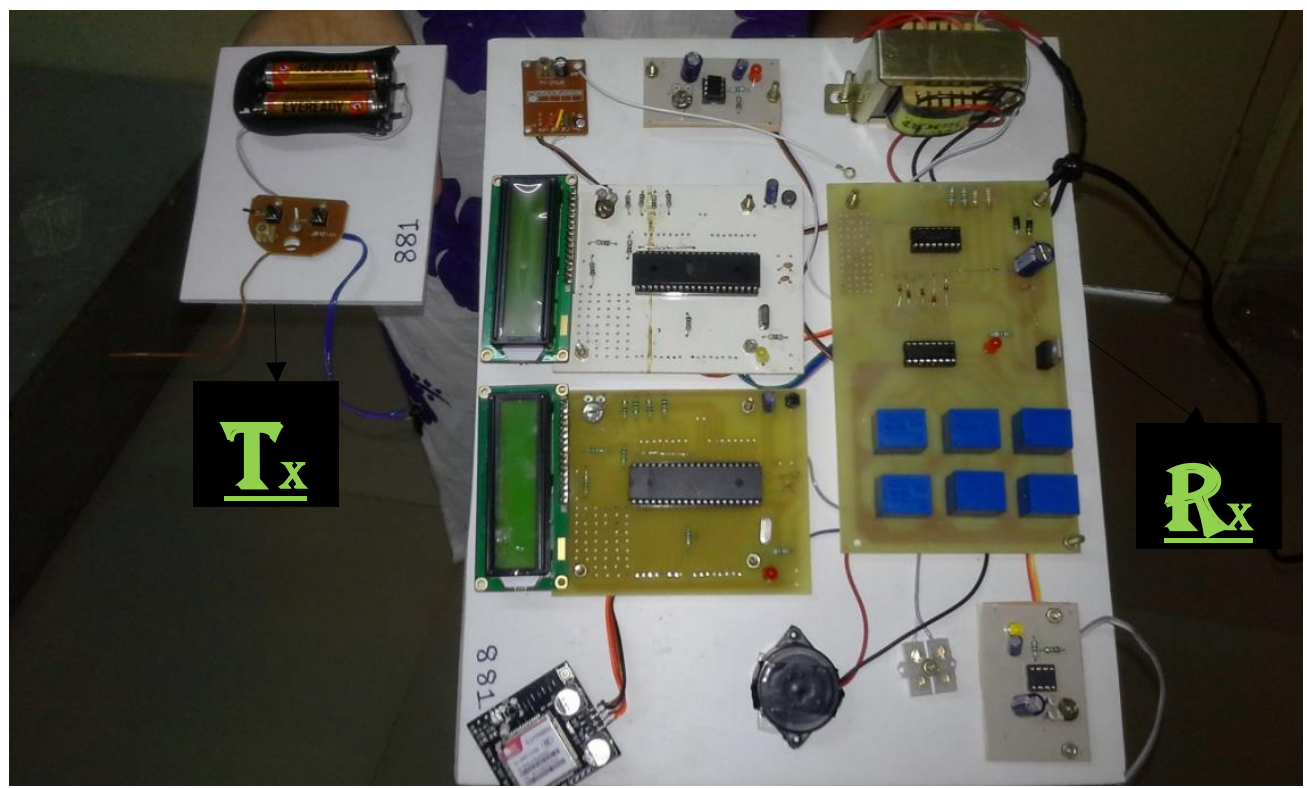

Figure 3: Live prototype model of proposed system

\section{Result and Future Enhancement}

The proposed system encapsulates solutions, which is intended for every disadvantages persisted previously. With the help of this application, the load of unwanted burdens of the display of energy-meter-reader along the Electricity-Board will be diminished and will be improved to be efficient. A mobile-solution can be given to the energy-meter-reader such that the daily-work becomes less burdened. Maximum of manual-processes and encapsulations are discarded resulting in the meter-readings which can be easily collected and more accurately as it has to be uplinked to the respective controls. At the same time, Android-consumers can also be given a 
Recent Advances in Communication, Electronics \& Electrical Engineering mobile-solution and hence to view their own recent-bills, lodging the grievance against the Electricity Board's service if any, and pay bills or any other required tasks relatively. Administration-works of the concerned Board might also be done via, a Web-site which is an extended part of the complete-project. For future enhancement, image-processing can be done in any motile-device along with the image been captured simultaneously. Afterwards few numeric data, collected based on those images can be uploaded to respective server created for the requirement.

The proposed system is been well-tested and evaluated that, it functions proper and accurate such that, concerned electricity-board can provide its customers with satisfactory service with the employment of proposed system as the solution for existing grievance. This proposal has various advantages except that; it is a 'one-time investment' system.

\section{Applications and Conclusions}

\section{Applications}

- The Real-time Power monitoring at houses.

- Sensing the power-pilferage, at the exact-location.

- Transmitting the information, over wireless, to substations.

- It can be used in domestic-households.

- It can be implemented in malls, where huge amounts-of power are wasted.

- It can also be implemented in, schools and colleges.

- The system can be incorporated for almost all-the-types of users.

- The concept is well suited. especially for villages and interior-areas

\section{Conclusion}

Electricity theft (or pilferage) leads to commercial-loss involving: tampering of energy-meters to miss-lead bill-information or direct-connections to power-lines. It's impossible to read the Commercial-losses by employing good-old power-system analysis-techniques because of the weak information of commercial and the genuine loads in the market-system, which is insufficient-for any valuable calculations of persisting losses. The hard efforts to find commercial-losses are in-accurate since the figures are redundant in the records of detectedcases, rather than by actual measurement of the electrical-power system. Employment of proposed system may lead to the betterment of power utilization. All the civilians are affected by power pilferage where, the detection and reporting illegitimate-activities might surely provide a hand to reduce the price paid which would be full-filled successfully by the proposed system involving 'automated message alert' and 'load-cutoff' whenever tampering attempts are made to energy-meters.

\section{Acknowledgement}

We would like to thank Mr.Krishnananda, Assistant Professor, Dayananda Sagar College of Engineering, Bangalore for his valuable inputs. 
Recent Advances in Communication, Electronics \& Electrical Engineering

\section{References}

[1] A. Abdullah, M. Dehghani, and N. Zamanzadeh, "SMS-BASED RECONFIGURABLE AUTOMATIC METER READING SYSTEM,", IEEE International Conference on Control Applications (CCA 2007), Oct, 2007, pp. 1103 - 1107.

[2] C. Jägerlind, "IMPROVEMENTS FOR THE AUTOMATIC METER READING PROCESS IN ELECTRICITY DISTRIBUTION COMPANIES", Master Thesis, Dep. Industrial Info and Control Systems, Royal Institute of Technology, Stockholm, Sweden 2006.

[3] C. Nunn, P. Moore, \& P. Williams "REMOTE METER READING AND CONTROL USING HIGH- PERFORMANCE PLC COMMUNICATION OVER THE LOW VOLTAGE AND MEDIUM VOLTAGE DISTRIBUTION NETWORKS", in 7th International Conference on Metering Apparatus and Tariffs for Electricity Supply, 1992, pp. 304-308.

[4] Wikipedia source: https://en.wikipedia.org/wiki/Theft_of_electricity

[5] L. Cao, J. Tian, and Y. Liu, "REMOTE WIRELESS AUTOMATIC METER READING SYSTEM BASED ON WIRELESS MESH NETWORKS AND EMBEDDED TECHNOLOGY", Fifth IEEE International Symposium on Embedded Computing, 2008. SEC '08, Oct, 2008, pp. $192-197$.

[6] M. Venables, "SMART METERS MAKE SMART CONSUMERS", IET Engineering and Technology, Vol. 2, No. 4, p.23, April 2007.

[7] Wikipedia Page (22/9/2010) [Online] available: http://en.wikipedia.org/wiki/Automatic_meter_reading

[8] P. Palensky and Ge. Pratl, "SECURE AND SCALABLE AUTOMATED METER READING", Domestic Use of Energy Conference 2003, pp. 233-23

\footnotetext{
*Corresponding author.

E-mail address: saisupriyagkgk@gmail.com
} 